\title{
Serum Proinsulin in Normal and Gestational Diabetic Pregnancy
}

\author{
C. Kühl \\ Dept. of Internal Medicine (T), Bispebjerg Hospital and Diabetes Centre, Dept. of Obstetrics and Gynaecology (Y), Rigshospitalet, Univ. of \\ Copenhagen, Copenhagen, Denmark
}

Summary. The concentration of proinsulin-like components (PLC) in serum has been determined by gel filtration on samples obtained from eight normal pregnant women and eight nonobese gestational diabetics. The normal women were investigated early in pregnancy and all subjects were investigated in mid pregnancy, late pregnancy, and postpartum. At each occasion, samples were obtained after an overnight fast and after glucose ingestion. In both groups, the concentration of PLC in serum after overnight fast rose with gestation as well as after glucose ingestion, but there were no significant differences between mean levels of PLC of the normals and the gestational diabetics. With gestation, serum insulin rose in parallel with PLC in either group. The proportion of total insulin immunoreactivity composed by PLC thus remained constant and, furthermore, the proportions of PLC in gestation were equal to those observed postpartum. Four to six weeks after delivery, the basal concentration of PLC in serum was higher in the gestational diabetics than in the normals, whereas the concentrations of insulin were equal. Since the biological potency of proinsulin is much less than that of insulin, the results exclude the possibility that the decrease of glucose tolerance in normal pregnant women and gestational diabetics is due to an increased concentration of proinsulin in serum.

Key words: Proinsulin, insulin, pregnancy, diabetes in pregnancy.

In pregnant rats the islets of Langerhans are hypertrophic, mainly due to hyperplasia of the B-cells $[8,9$, 27], and the B-cells contain increased numbers of secretory granules [1]. These changes correspond well with the elevated concentrations of immunoreactive insulin in plasma of pregnant rats $[16,23]$ and of women $[2,10,11,15,22]$. Also proinsulin is secreted by B-cells and circulates in the blood [20,21]. Because proinsulin and its intermediates (proinsulin-like components, PLC) [25] cross-react with the insulin antibodies in the radioimmunoassay, but are biologically much less active than insulin $[14,26]$, it might be assumed that the elevated levels of insulin immunoreactivity in sera of pregnant women simply reflect an increased share of PLC in the total immunoreactivity. This might explain the apparent ineffectiveness of the enhanced serum insulin concentrations in maintaining normal glucose tolerance in pregnancy.

Accordingly, insulin and PLC levels in sera obtained during pregnancy have been compared to the levels postpartum in the same subjects; this paper gives data on normal pregnant women and nonobese gestational diabetics.

\section{Materials and Methods}

\section{Subjects}

Eight healthy, nonobese, aglucosuric pregnant women with normal basal blood glucose concentrations and aged 22-33 (mean 26.4) years were investigated in early pregnancy (i. e. between week 13 and 19 of gestation), mid pregnancy (i. e. between week 22 and 28 of gestation), and late pregnancy (i. e. between week 35 and 38 of gestation). Four to six weeks after delivery a post-pregnancy control test was carried out. Prior to the actual pregnancy all subjects were within $10 \%$ of their ideal body weight [17] and none had a family history of diabetes. The average parity was 0.6 (range $0-1$ ). Each woman gave birth to a healthy 


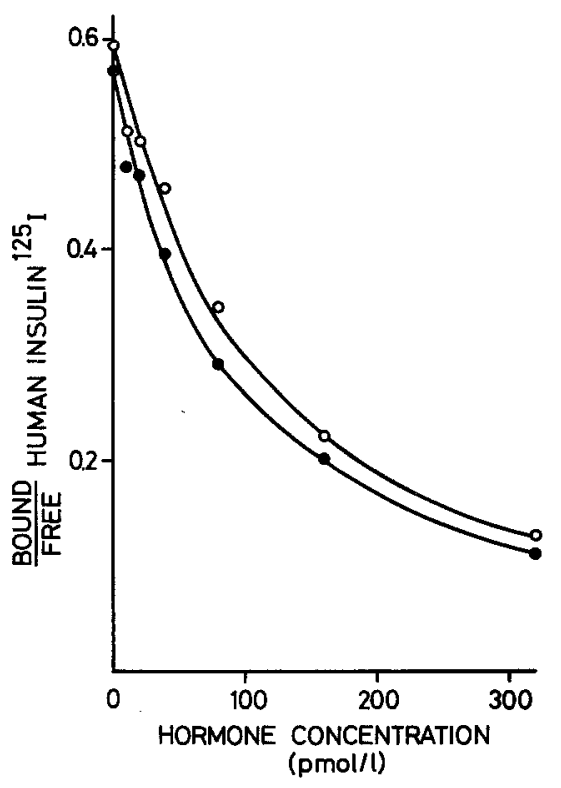

Fig. 1. Standard calibration curves of human insulin $(\bullet \bullet)$ and porcine proinsulin $(0-0)$ using an antiporcine insulin antiserum and human ${ }^{125} \mathrm{I}$-insulin

infant of normal birth weight (mean $3350 \mathrm{~g}$; range 2650-3800) at term. Eight nonobese gestational diabetics aged 23-39 (mean 30.1) years were investigated in mid and late pregnancy, and again four to six weeks postpartum. By gestational diabetics is understood women who (a) have a normal basal blood glucose concentration, but (b) diabetes diagnosed for the first time from an oral glucose tolerance test (OGTT) in pregnancy, and (c) a non-diabetic OGTT after delivery. At least two glucose values of the OGTTcurves of the gestational diabetics exceeded the mean +3 SD curve pertaining to a group of 46 normal non-pregnant controls investigated by exactly the same procedure [11]. All subjects in this group were treated with diet only and, prior to the actual pregnancy, they were of normal weight and within $10 \%$ of their ideal body weight [17]. Four subjects had close relatives with diabetes. The average parity of the gestational diabetics was 1.4 (range $0-3$ ).

The women either had spontaneous vaginal delivery 1-4 weeks before term (4 subjects) or medically induced vaginal delivery about one week before term (4 subjects). All infants were healthy with a mean birth weight of $3144 \mathrm{~g}$ (range $2400-4200$ ). The normals and the gestational diabetics did not differ significantly as regards their mean body weight, weight gain during pregnancy or age. Nor did the mean birth weight of the offspring differ. The average parity of the gestational diabetics was higher than that of the normals $(p<0.05)$. Informed consent was obtained from all subjects.

\section{Experimental Procedure}

Diuretics were given to a few of the subjects because of slight ankle oedema, but in these cases the treatment was always discontinued for a minimum of one week before investigations. All subjects were on a normal full diet for at least three days before tests, which were performed in the morning after a $10-12 \mathrm{~h}$ fast and abstinence from smoking. Immediately upon arrival an intravenous cannula was inserted into an antecubital vein. After a 20 min rest a basal sample was drawn and subsequently the subject was given 50 $\mathrm{g}$ of glucose as a $25 \%$ solution flavoured with lemon. Sixty minutes after glucose loading a second sample was drawn. Sera were stored at $-25^{\circ} \mathrm{C}$ until further procedures were initiated.

\section{Laboratory Analyses and Calculations}

Gel Filtration. PLC and insulin in serum were separated by gel chromatography on columns of Sephadex G-50 superfine $(9 \times 600 \mathrm{~mm})$ eluted with $0.25 \mathrm{M}$ ammoniumbicarbonate, $\mathrm{pH} 8.2$, with a constant flow rate of $3.8 \mathrm{ml} / \mathrm{h}$ (Peristaltic Pump P-3, Pharmacia, Sweden). Samples of $0.5 \mathrm{ml}$ of the basal serum and the corresponding serum obtained 1 hour after glucose administration were applied to two identical columns and eluted in parallel by the same pump. Fractions of $1.5 \mathrm{ml}$ were collected for radioimmunoanalysis and those corresponding to the elution volumes of highly purified porcine proinsulin and human insulin standards (NOVO Research Institute, Copenhagen) were pooled separately and concentrated by lyophilization. Since this procedure does not separate proinsulin from its closely related intermediates [25], the material corresponding to the elution volume of the proinsulin standard was designated proinsulin-like components (PLC). Aliquots of the serum samples that had been applied to the columns were assayed in the same assay as the column fractions. A recovery of $90-105 \%$ of the insulin immunoreactivity applied to the columns was found.

Immunoassay. After lyophilization the column pools were dissolved in $0.04 \mathrm{M}$ phosphate buffer, $\mathrm{pH} 8$, containing $0.06 \mathrm{mM}$ sodium methiolate, $0.9 \mathrm{~g} / 100 \mathrm{ml}$ sodium chloride and $5 \mathrm{~g} / 100 \mathrm{ml}$ bovine albumin. All PLC and insulin pools from one individual were assayed in the same radioimmunoassay. The assay uses wick chromatography for separation and human Mono-Component insulin (NOVO Research Institute, Copenhagen) standards. Detection limit, precision and accuracy of the assay have been given in detail elsewhere [11]. The guinea pig porcine insulinantiserum used in the present study (4346) binds 
proinsulin and insulin with almost equimolar potency (Fig. 1). The sensitivity of the insulin assay, was in the present study, $2 \mathrm{pmol} / 1$ serum.

Calculations. For calculation purposes the proportion of the total insulin immunoreactivity in serum composed by PLC is defined as picomoles insulin immunoreactivity recovered in the PLC pool divided by the sum of picomoles insulin immunoreactivity recovered in the PLC and insulin pools.

Within the groups (normal or gestational diabetics) significance of differences between means was tested by Students $t$-test for paired observations, while data originating from both groups were compared by Students $t$-test for unpaired observations. Differences resulting in p-values less than 0.05 were considered significant.

\section{Results}

Molar concentrations of insulin and PLC in serum are given in Tables 1 and 2, while Table 3 gives average values of PLC expressed as proportions of total insulin immunoreactivity in serum.

\section{Concentrations in Serum after an Overnight Fast}

Basal insulin concentrations increased during gestation in the normals as well as in the gestational diabetics, but the increment was only significant in the normals $(\mathrm{p}<0.01)$. However, compared to postpartum, insulin levels were significantly enhanced in mid and late pregnancy in both groups (Table 1). In mid pregnancy, the mean basal insulin concentration of the gestational diabetics was higher than that of the normals $(p<0.05)$. Basal PLC concentration also rose in gestation, but, again, the increment was only significant in the normals $(p<0.01)$. Compared to postpartum, serum levels of PLC were enhanced in normal mid and late pregnancy (Table 2). Postpartum, the mean serum PLC concentration of the gestational diabetics was higher than that of the normals $(p<0.05)$.No significant changes were observedduring gestation in the proportion of total insulin immunoreactivity composed by PLC in either group, nor did the values observed during pregnancy differ from the corresponding postpartum values (Table 3 ).

\section{Concentrations in Serum 1 Hour after Oral Intake of $50 \mathrm{~g}$ of Glucose}

Glucose ingestion was always followed by a rise in the mean serum insulin concentration, the rise being greatest in late pregnancy. In mid gestational diabetic pregnancy and late normal and gestational diabetic pregnancy mean serum insulin concentrations were all higher than the corresponding postpartum values (Table 1). Serum PLC concentration also rose after glucose administration $(\mathrm{p}<0.05)$ except in mid pregnancy and postpartum in the gestational diabetics.

Compared to postpartum the mean concentration of PLC in serum was enhanced in late normal and gestational diabetic pregnancy (Table 2). No differences were observed between corresponding PLC levels in the normals and the gestational diabetics. The proportion of total insulin immunoreactivity composed by PLC was not influenced by pregnancy, nor did the mean values of the two groups differ (Table 3 ).

\section{Discussion}

The present study has shown that normal pregnant women and nonobese gestational diabetics had comparable absolute levels and proportions of PLC in serum after an overnight fast as well as 1 hour after glucose ingestion. In both groups, PLC levels were enhanced during gestation. PLC did not, however, constitute an abnormal proportion of the total insulin immunoreactivity, since insulin increased equally and hence counterbalanced the enhanced PLC levels. After termination of pregnancy absolute levels of PLC in serum were higher during the fasting state in the gestational diabetics than in the normals. However, since the basal concentration of insulin in the serum of the gestational diabetics also exceeded that of the normals postpartum (non significant) the proportion of the total insulin immunoreactivity constituted by PLC was the same in both groups (Table 3).

Elevated pro-insulin concentrations after an overnight fast and glucose stimulation have previously been reported by many laboratories $[2,10,15,22,24]$ including ours $[11,12]$. The finding of a normal proportion of PLC in late normal pregnancy and late gestational diabetic pregnancy confirms the recent findings by Phelps et al. [18], whereas until now no reports concerning PLC levels in normal early and mid pregnancy and mid gestational diabetic pregnancy have been published.

In accordance with our results, normal levels of PLC have been described in children and adolescents with chemical diabetes [19] and young adults with idiopathic glucose intolerance [7] associated with normal concentrations of insulin in serum. On the other hand, slightly elevated basal and postglucose PLC levels have also been reported in chemical juvenile [3] and adult [6] diabetics. Borderline diabetics, however, had normal PLC levels [6]. It should be stressed that 

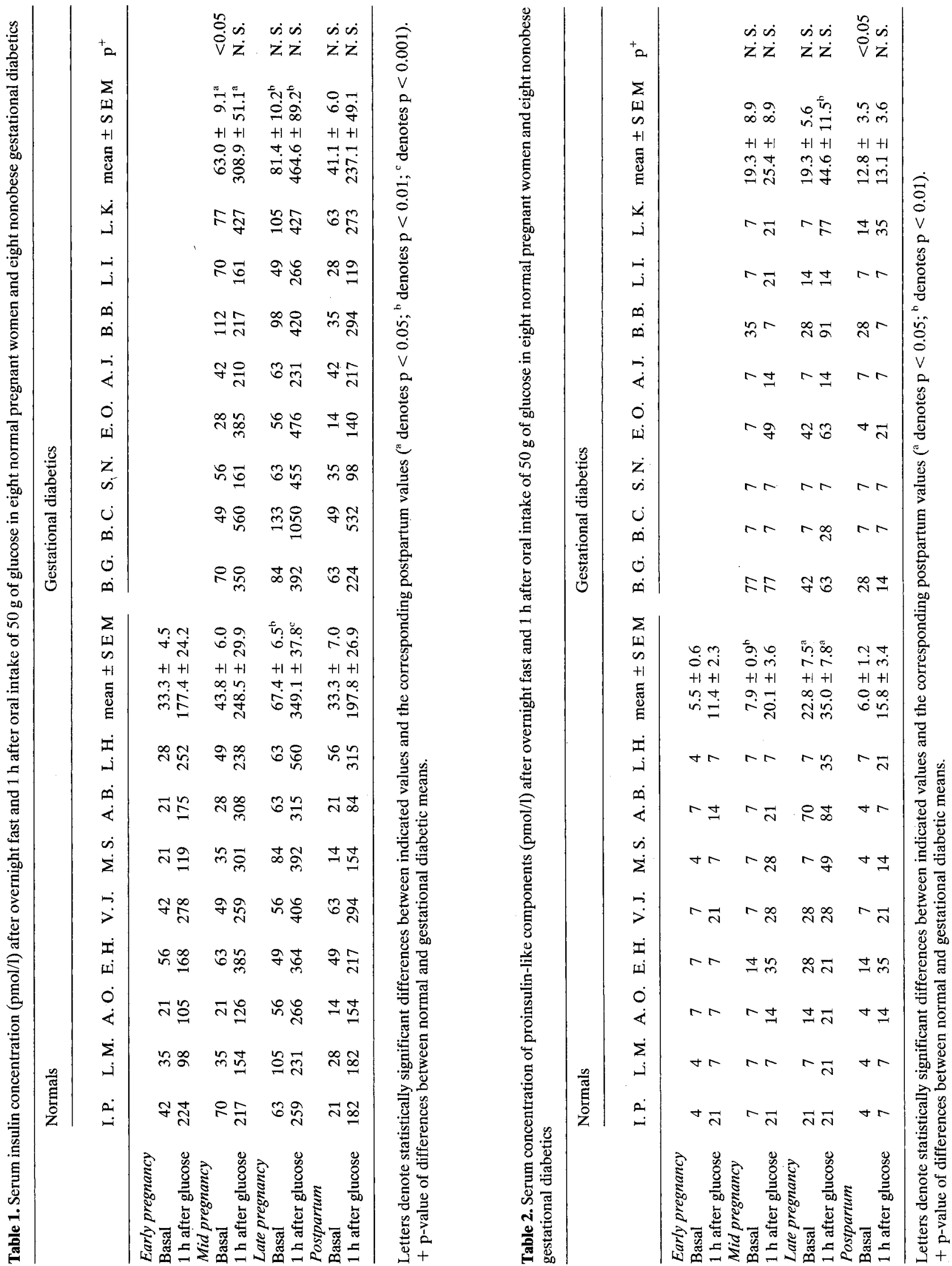
Table 3. Proportion of total insulin immunoreactivity composed by proinsulin-like components. Values shown are mean $\pm \mathrm{SE} M(\mathrm{~N}=8$ in both groups)

\begin{tabular}{|c|c|c|c|}
\hline & Normals & Gestational diabetics & Level of significance \\
\hline \multicolumn{4}{|l|}{ Early pregnancy } \\
\hline Basal & $0.15 \pm 0.02$ & & \\
\hline $1 \mathrm{~h}$ after glucose & $0.06 \pm 0.01$ & & \\
\hline \multicolumn{4}{|l|}{ Mid pregnancy } \\
\hline Basal & $0.17 \pm 0.02$ & $0.19 \pm 0.05$ & N. S. \\
\hline $1 \mathrm{~h}$ after glucose & $0.07 \pm 0.01$ & $0.08 \pm 0.02$ & N. S. \\
\hline \multicolumn{4}{|l|}{ Late pregnancy } \\
\hline Basal & $0.24 \pm 0.06$ & $0.19 \pm 0.05$ & N.S. \\
\hline $1 \mathrm{~h}$ after glucose & $0.09 \pm 0.02$ & $0.09 \pm 0.02$ & N. S. \\
\hline \multicolumn{4}{|l|}{ Postpartum } \\
\hline Basal & $0.17 \pm 0.02$ & $0.22 \pm 0.04$ & N. S. \\
\hline $1 \mathrm{~h}$ after glucose & $0.07 \pm 0.01$ & $0.06 \pm 0.01$ & N. S. \\
\hline
\end{tabular}

the two latter studies $[3,6]$ employed a proteolytic enzyme assay for proinsulin. PLC estimations obtained by enzyme assay correlate only partly with those obtained by gel filtration assays [4]. Thus, slight discrepancies between the findings of the present study and those cited above $[3,6]$ might be ascribed to different assay techniques.

In conclusion, the diminished glucose tolerance in normal pregnant women and nonobese gestational diabetics was not associated with an abnormally elevated proportion of total insulin immunoreactivity composed by PLC.

This finding, taken with the recent finding of normal secretion of glucagon in normal pregnant women or gestational diabetics $[5,12,13]$, contradicts the suggestion that changes in the function of the endocrine pancreas explain the diabetogenicity of pregnancy. Therefore, alternative hypotheses, especially concerning the effect of pregnancy on the action of insulin and glucagon upon the liver and peripheral tissues, have to be explored.

Acknowledgements. The technical assistance of Helene Arndal and Connie Breiner and the typing of the manuscript by Rigmor Hansen is gratefully acknowledged. The investigation was supported by grants from the Danish Medical Research Council (jr. no. 512-1939, 512-3083, 512-4202 and 512-5738), the Medical Research Council for Copenhagen, the Faroe Islands and Greenland, and the Novo Foundation.

\section{References}

1. Aerts, L., Van Assche, F. A.: Ultrastructural changes of the endocrine pancreas in pregnant rats. Diabetologia 11, 285-289 (1975)

2. Bleicher, S. J., O'Sullivan, J. B., Freinkel, N.: Carbohydrate metabolism in pregnancy. $\mathrm{V}$. The interrelations of glucose, insulin and free fatty acids in late pregnancy and postpartum. New Engl. J. Med. 271, 866-872 (1964)

3. Burghen, G. A., Etteldorf, J. N., Trouy, R. L., Kitabchi, A. E.: Insulin and proinsulin secretion in chemical and overt juvenile diabetics. Pediat. Res. 7, 325 (1973)

4. Cresto, J. C., Lavine, R. L., Fink, G., Recant, L.: Plasma proinsulin: Comparison of insulin specific protease and gel filtration assays. Diabetes 23, 505-511 (1974)

5. Daniel, R. R., Metzger, B. E., Freinkel, N., Faloona, G. R., Unger, R. H., Nitzan, M.: Carbohydrate metabolism in pregnancy. XI. Response of plasma glucagon to overnight fast and oral glucose during normal pregnancy and in gestational diabetes. Diabetes 23, 771-776 (1974)

6. Duckworth, W. C., Kitabchi, A. E., Heinemann, M.: Direct measurement of plasma proinsulin in normal and diabetic subjects. Amer. J. Med. 53, 418-427 (1972)

7. Gorden, P., Roth, J.: Plasma insulin: Fluctuations in the 'big' insulin component in man after glucose and other stimuli. $J$. clin. Invest. 48, 2225-2234 (1969)

8. Green, I. C., Taylor, K. W.: Effects of pregnancy in the rat on the size and insulin secretory response of the islets of Langerhans. J. Endocr. 54, 317-325 (1972)

9. Hellman, B.: The islets of Langerhans in the rat during pregnancy and lactation, with special reference to the changes in the B/A cell ratio. Acta obstet. gynec. scand. 39, 331-342 (1960)

10. Kalkhoff, R., Schalch, D. S., Walker, J. L., Beck, P., Kipnis, D. M., Daughaday, W. H.: Diabetogenic factors associated with pregnancy. Trans. Ass. Amer. Phycns 77, 270-279 (1964)

11. Kühl, C.: Glucose metabolism during and after pregnancy in normal and gestational diabetic women. I. Influence of normal pregnancy on serum glucose and insulin concentration during basal fasting conditions and after a challenge with glucose. Acta Endocr. (Kbh.) 79, 709-719 (1975)

12. Kühl, C., Holst, J. J.: Plasma glucagon and the insulin: Glucagon ratio in gestational diabetes. Diabetes 25, 16-23 (1976)

13. Kühl, C., Hornnes, P., Klebe, J. G.: Effect of protein ingestion on glucagon and insulin release in normal pregnancy. (Submitted for publication 1976)

14. Lazarus, N. R., Penhos, J. C., Tanese, T., Michaels, L., Gutman, R., Recant, L.: Studies on the biological activity of porcine proinsulin. J. clin. Invest. 49, 487-496 (1970)

15. Lind, T., Billewicz, W. Z., Brown, G.: A serial study of changes occurring in the oral glucose tolerance test during pregnancy.J. Obstet. Gynaec. Brit. Cwlth 80, 1033-1039 (1973)

16. Metzger, B., Pek, S., Hare, J., Freinkel, N.: Relationships between glucose, insulin and glucagon during fasting in late gestation in the rat. Life Sci. 15, 301-308 (1974) 
17. Natvig, H.: Nye hoyde-vekttabeller for norske kvinner og menn. Oslo: Landsforeningen for kosthold og helse 1956

18. Phelps, R. L., Bergenstal, R., Freinkel, N., Rubenstein, A. H., Metzger, B. E., Mako, M.: Carbohydrate metabolism in pregnancy: XIII. Relationships between plasma insulin and proinsulin during late pregnancy in normal and diabetic subjects. J. clin. Endocr. 41, 1085-1091 (1975)

19. Rosenbloom, A. L., Starr, J. I., Juhn, D., Rubenstein, A. H.: Serum proinsulin in children and adolescents with chemical diabetes. Diabetes 24, 753-757 (1975)

20. Roth, J., Gorden, P., Pastan, I.: 'Big insulin': A new component of plasma insulin detected by immunoassay. Proc. nat. Acad. Sci. (Wash.) 61, 138-145 (1968)

21. Rubenstein, A. H., Cho, S., Steiner, D. F.: Evidence for proinsulin in human urine and serum. Lancet $1968 \mathrm{I}, 1353-1355$

22. Samaan, N. A., McRoberts, W. A., Smith, J. P., Myers, L. G.: Metabolic changes in women with trophoblastic disease and with intrauterine fetal death compared with metabolic changes during normal pregnancy. J. clin. Endocr. 33, 521-529 (1971)

23. Saudek, D. C., Finkowski, M., Knopp, R. H.: Plasma glucagon and insulin in rat pregnancy. Roles in glucose homeostasis. J. clin. Invest. 55, 180-187 (1975)
24. Spellacy, W. N., Goetz, F. C.: Plasma insulin in normal late pregnancy. New Engl. J. Med. 268, 988-900 (1963)

25. Steiner, D. F., Hallund, O., Rubenstein, A., Cho, S., Bayliss, C.: Isolation and properties of proinsulin, intermediate forms, and other minor components from crystalline bovine insulin. Diabetes 17, 725-736 (1968)

26. Sönksen, P. H., Tompkins, C. V., Srivastava, M. C., Nabarro, J. D. N.: A comparative study of the metabolism of human insulin and porcine proinsulin in man. Clin. Sci. Mol. Med. 45, 633-654 (1973)

27. Van Assche, F. A.: Quantitative morphologic and histoenzymatic study of the endocrine pancreas in nonpregnant and pregnant rats. Amer. J. Obstet. Gynec. 118, 39-41 (1974)

Received: January 29, 1976, and in revised form: April 21, 1976

Dr. C. Kühl

Dept. of Internal Medicine (T)

Bispebjerg Hospital

23 Bispebjerg Bakke

DK-2400 Copenhagen NV

Denmark 